\title{
Eurasian Arctic greening reveals teleconnections and the potential for novel ecosystems
}

\author{
Marc Macias-Fauria', Bruce C. Forbes ${ }^{2 \star}{ }^{1}$ Pentti Zetterberg ${ }^{3}$ and Timo Kumpula ${ }^{4}$
}

Arctic warming has been linked to observed increases in tundra shrub cover and growth in recent decades ${ }^{1-3}$ on the basis of significant relationships between deciduous shrub growth/biomass and temperature ${ }^{3-7}$. These vegetation trends have been linked to Arctic sea ice decline ${ }^{5}$ and thus to the sea ice/albedo feedback known as Arctic amplification ${ }^{8}$. However, the interactions between climate, sea ice and tundra vegetation remain poorly understood. Here we reveal a 50year growth response over a $>100,000 \mathrm{~km}^{2}$ area to a rise in summer temperature for alder (Alnus) and willow (Salix), the most abundant shrub genera respectively at and north of the continental treeline. We demonstrate that whereas plant productivity is related to sea ice in late spring, the growing season peak responds to persistent synoptic-scale air masses over West Siberia associated with Fennoscandian weather systems through the Rossby wave train. Substrate is important for biomass accumulation, yet a strong correlation between growth and temperature encompasses all observed soil types. Vegetation is especially responsive to temperature in early summer. These results have significant implications for modelling present and future Low Arctic vegetation responses to climate change, and emphasize the potential for structurally novel ecosystems to emerge from within the tundra zone.

Within the Arctic, northwestern Eurasian tundra (NWET) is unique in being one of the warmest regions, as measured by the summer warmth index (that is, growing season temperature) ${ }^{9}$, and in having highly variable sea ice, lower overall than other Arctic seas, owing to the direct influence of atmosphere and ocean heat transport through the North Atlantic storm track ${ }^{10}$. The normalized difference vegetation index ${ }^{11}$ (NDVI), a decadal satellite-based proxy for vegetation productivity, highlights most of NWET as extremely productive, with a sharp productivity drop in the geologically distinct Yamal, Gydan and Taz peninsulas ${ }^{12,13}$ (Fig. 1). Tree-sized, tall (>2 m) deciduous shrubs (mainly Salix ${ }^{6}$ ) have developed in recent decades within the region, demonstrating an in situ change of the Low Arctic tundra structure that is quantifiable but has also been observed in detail by indigenous Nenets reindeer herders both west and east of the Polar Ural Mountains ${ }^{14}$. NWET is thus now experiencing environmental and ecological conditions likely to soon develop across other Arctic regions if the ongoing warming trend continues, and can be seen in this respect as a bellwether of the tundra biome. Extensive oil and gas development amidst huge herds of reindeer (Rangifer tarandus L.) that heavily exploit willow-dominated shrub tundra for spring, summer and autumn forage ${ }^{15}$ further reinforces the vision of the region as an example of the likely future in the Arctic. For all of these reasons, NWET is an optimal area to: investigate large-scale responses to decadal warming through in situ phenotypic Q3 48 changes in plant individuals representing different areas, substrates $\quad 49$ and species; and partition among and characterize the respective intra-seasonal drivers of these vegetation changes.

To address these questions, we conducted an extensive study encompassing remote sensing, climate and sea ice data, ring-width chronologies of tall individuals from two abundant and nearly circumpolar deciduous shrub species in the Low Arctic (Salix lanata L. and Alnus fruticosa Rupr.), and intensive ground truthing over three sites across the Low Arctic of NWET (Fig. 1). Our results strongly suggest that recent sea ice retreat has had a limited influence on tundra productivity in the region, and that the growth of tall shrubs is ultimately related to the position of continental air masses in July. For the period 1982-2005, NWET greenness (as measured by NDVI at $8 \mathrm{~km}$ resolution ${ }^{11}$ ) was related to sea ice cover only in late spring (May and early June), when NDVI values in NWET were still low ( $<0.3$ in all cases; Fig. 2a). Spatiotemporal relationships between temperature and the Barents and Kara seas ice area reflected a similar pattern, with a strong effect of sea ice on adjacent land in spring followed by no effect during the summer months (Fig. 2b). Tall shrub growth was highly correlated to July NDVI $\left(p<0.01, r^{2}\right.$ ranging regionally from 0.4 to 0.75 ; Fig. 3 and Supplementary Fig. S1). Shrub dendrochronologies, well replicated for a longer period covering the second half of the twentieth century up to 2005, responded very strongly to summer temperatures (Supplementary Fig. S2). Their correlation fields indicated teleconnection patterns over a vast region with a positive pole over western Siberia and a negative one over Fennoscandia (Fig. 4a and Supplementary Fig. S3). This pattern corresponds to the summer Scandinavian Pattern ${ }^{16}$ (SCA), which consists of a primary circulation centre over Fennoscandia, with a weaker centre of opposite sign over the western and central Siberian lowlands, and with prominent subtropical components to the northwest of the Indian monsoon region ${ }^{17}$. SCA showed a remarkable agreement with patterns of NWET peak growing season NDVI with a lag of less than a month $\left(p<0.01, r^{2}\right.$ ranging regionally from 0.4 to 0.69; Fig. 4b), and with temperatures across NWET (Fig. $4 \mathrm{c}$ and Supplementary Fig. S4a), in agreement with previously observed lags between temperature and NDVI in the region ${ }^{6}$. Correlations were especially strong towards the east, coinciding with the Siberian SCA pole. A negative SCA is characterized by an upper air blocking high over west-central Siberia that enhances subsidence and warm air advection into NWET (Supplementary Fig. S4a). Summer SCA has shown a decadal negative trend since its index began to be computed in 1950 (Supplementary Fig. S4b), whereas summer temperatures from meteorological stations and remote-sensing NDVI values within NWET have increased over the same period,

\footnotetext{
${ }^{1}$ Long-term Ecology Laboratory, Biodiversity Institute, Department of Zoology, University of Oxford, Tinbergen Building, South Parks Road, Oxford, OX1 3PS, UK, ${ }^{2}$ Arctic Centre, University of Lapland, Box 122, FI-96101 Rovaniemi, Finland, ${ }^{3}$ Laboratory of Dendrochronology, Department of Forest Sciences, University of Eastern Finland, Fl-80101 Joensuu, Finland, ${ }^{4}$ Department of Geographical and Historical Studies, University of Eastern Finland, Yliopistonkatu 7, FI-80101 Joensuu, Finland. *e-mail: bforbes@ulapland.fi.
} 


\section{$40^{\circ} \mathrm{E}$}

$60^{\circ} \mathrm{E}$

$70^{\circ} \mathrm{E}$

$80^{\circ} \mathrm{E}$

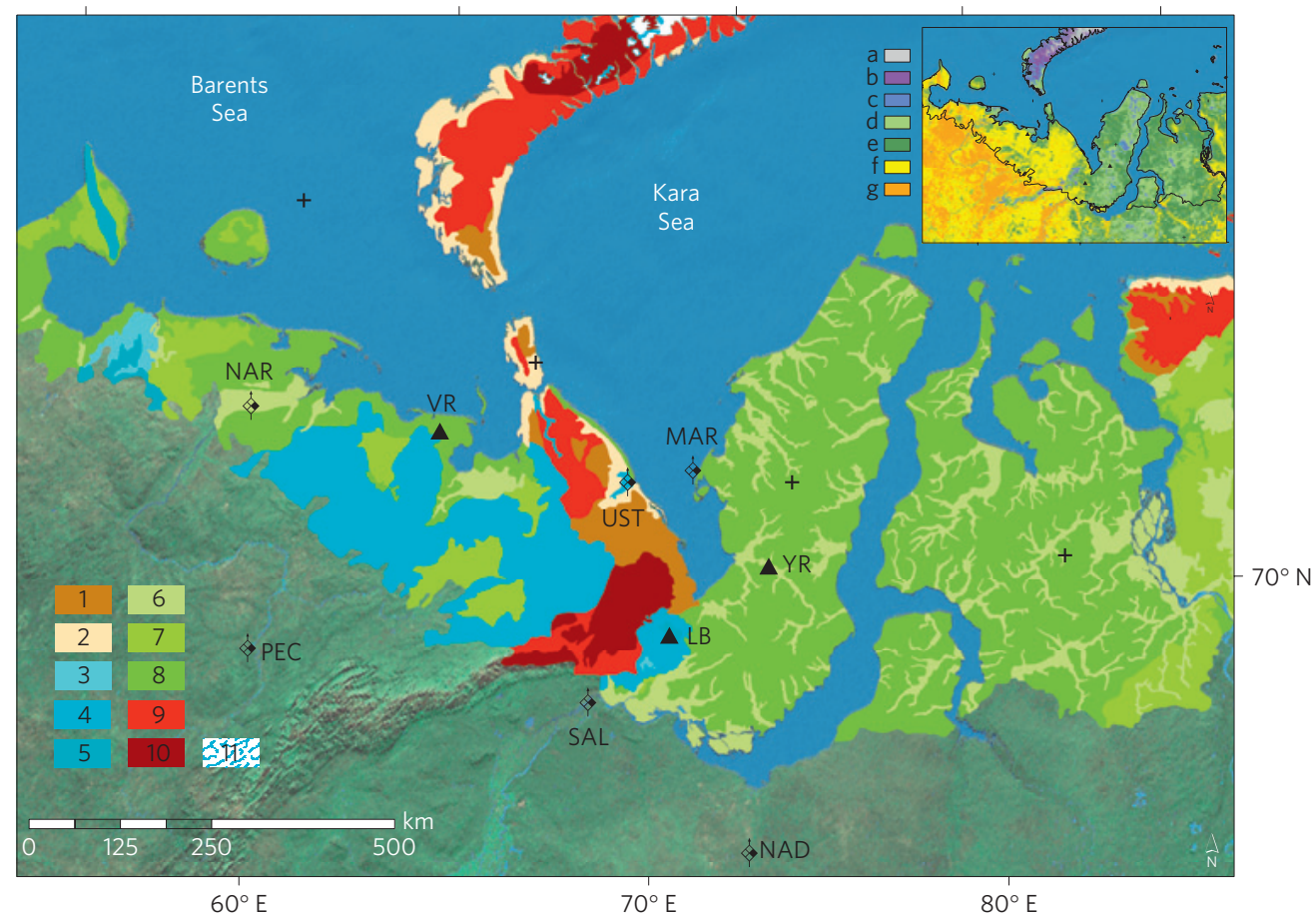

Figure 1 | Map of NWET. Sites where dendrochronologies were extracted are shown with a filled black triangle and two letters: VR, Varandei;

LB, Laborovaya; YR, Yuribei River. Meteorological stations <400 km away from the sites used in the computation of response functions are shown with a black rhomboid symbol and three letters: NAR, Naryan Mar; PEC, Pechora; SAL, Salekhard; UST, Ust Kara; MAR, Marre Sale; NAD: Nadym. Major landscape units and depositional origins are depicted for the tundra ${ }^{19}: 1,2$ : foothills, 1: glacial and glaciofluvial, 2: marine; 3-5: high plains and plateaux, 3: erosional-denudational, 4: glacial and glaciofluvial, 5: tablelands; 6-8: low plains, 6: fluvial, lacustrine, 7: glacial and glaciofluvial, 8: marine and ice-rich marine; 9,10: mountains, 9: erosional-denudational, 10: table mountains, mountain ranges; 11: ice caps and glaciers. Upper-right inset: circumpolar maximum NDVI of Arctic tundra. This image is a mosaic of AVHRR data portraying the maximum NDVI for each $1 \mathrm{~km}$ pixel during the summers of 1993 and 1995, 2 years of relatively low summer cloud cover in the High Arctic ${ }^{12}$. a: <0.03; b: 0.03-0.14; c: 0.15-0.26; d: 0.27-0.38; e: 0.39-0.50; f: 0.51-0.56; g: $>0.57$. Note the sharp contrast in productivity as seen by NDVI values and its spatial agreement with major changes in substrate.

showing similar overall spatial patterns, with stronger increases in the eastern part of NWET (Supplementary Fig. S5).

Moderate-Resolution Image Spectroradiometer NDVI data (250 $\mathrm{m}$ resolution, available for the period 2000-2010) strongly suggest that deciduous tall shrubs are a high-quality proxy for regional Low Arctic tundra biomass production, as seen in the good agreement between tall shrub NDVI and that of all other functional units in which we classified our study areas (Supplementary Fig. S6a,b). Dwarf, upland low shrub areas subject to heavy grazing pressure presented the same variability and similar (even higher) maximum NDVI values than tall, ungrazed shrubs. Shrub response to temperature has therefore not been restricted to tall shrubs in sheltered habitats. Phenological differences were however found in early summer, when tall shrub productivity was lower than that for adjacent upland dwarf shrubs (Supplementary Fig. S6c). This suggests a later onset of the growing season for tall shrubs due to their location in concave habitats where snow cover lasts longer than in upland areas ${ }^{18}$.

Quaternary sediment type and substrate composition strongly affect Low Arctic tundra productivity across a wide range of spatial scales, as seen in: the smaller growth of comparable S. lanata ring-width chronologies from nutrient-poor substrates, generally with high sand content, versus richer clay and silt-dominated soils under similar growing season temperature regimes (Supplementary Fig. S7a); and the large-scale dual pattern of NDVI in NWET, which strikingly coincides with the sharp transition from fluvial hillslopes and valleys west of the Ural Mountains (higher NDVI) to lowlands with marine sediments and continuous, often ice-rich permafrost east of them ${ }^{19}$ (lower NDVI; Fig. 1). Within Yamal (east of the Urals), productive areas, that is shrubbier and with higher NDVI, correspond to regions with topographically dissected valleys and extensive landslide activity ${ }^{18}$. Regardless of overall biomass accumulation due to differences in substrate, all ringwidth chronologies and overall NDVI variability were found to be strongly linked to summer temperature (Fig. 4a and Supplementary Figs S2, S3 and S5c). Nevertheless, the most productive areas were more inter-correlated (Fig. 3 and Supplementary Fig. S1). Both regional $(250 \mathrm{~m}$ resolution, $50 \times 50 \mathrm{~km})$ and local $(1 \mathrm{~m}$ resolution, $\sim 25-40 \mathrm{~km}^{2}$ ) land cover classifications revealed greater tall shrub cover west of the Urals. The tall shrub fraction ranged between $13 \%$ (west) and 6-8\% (east), whereas overall deciduous shrub cover was large everywhere and did not follow a westeast gradient (76-94\%, not taking into account water bodies; Supplementary Fig. S6a).

Biweekly NDVI data revealed high variability in the early growing season and a synchronous growth cessation (Supplementary Fig. S8a). This pattern of variability has been reported for northern high-latitude vegetation ${ }^{20}$ and does not correspond to differences in climatic variability between autumn and spring (Supplementary Fig. S8b). In cold-adapted tree species, the initiation of growth in spring occurs from buds when genetically determined winter chilling and spring heat sums are met, whereas bud set and height growth cessation occur when a genetically determined critical day length is experienced ${ }^{21}$. Photoperiod rather than temperature most likely limits vegetation growth at the end of the season. This suggests that an in situ response of tundra vegetation to climate warming might be restricted to the early growing season, whereas an autumn-extended growing season would depend 


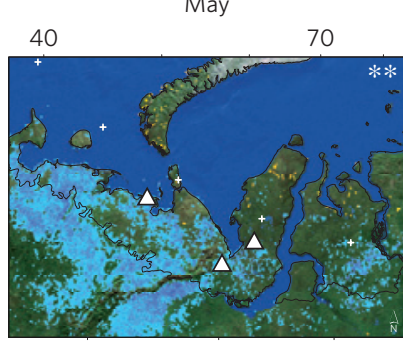

60

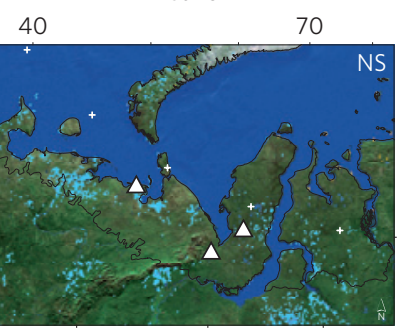

60

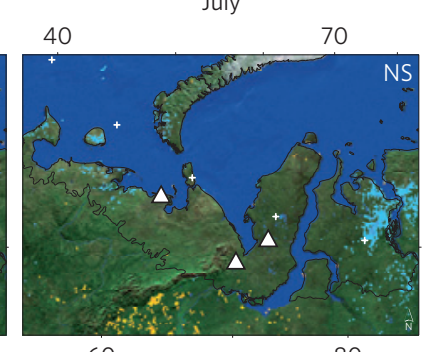

60

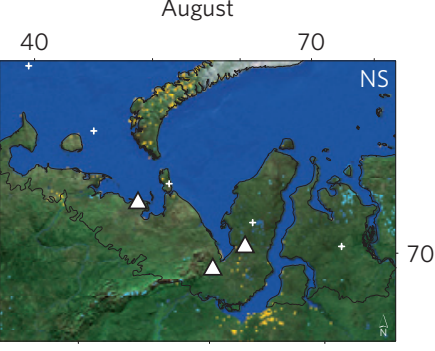

60

80

Pearson correlation coefficient $(r)$
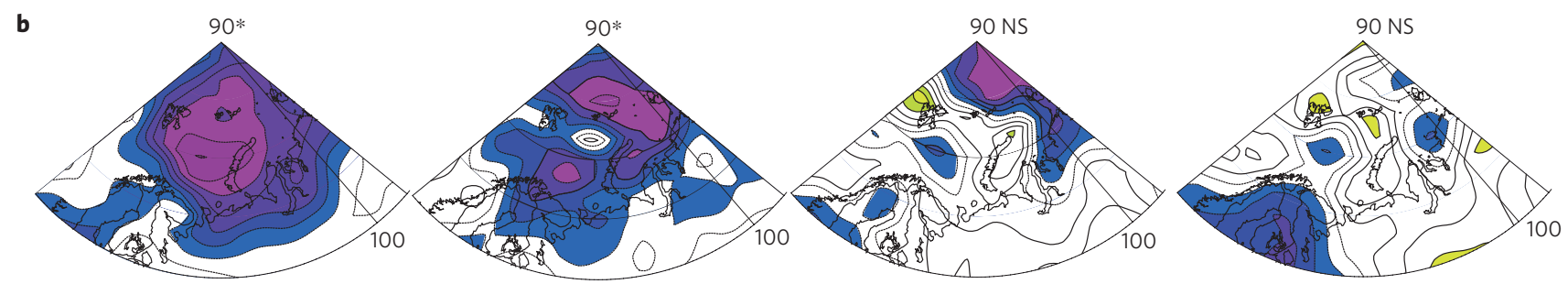

$-1.0$

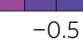

Pearson correlation coefficient ( $r$ )

Figure 2 | a, Monthly Pearson correlation coefficients ( $r$ ) between NDVI (ref. 11) and sea ice area in the Barents and Kara seas (http://nsidc.org/data/ nsidc-0079.html). Only significant ( $p<0.05$ ) correlations are shown. Study sites are shown as filled white triangles. b, Monthly Pearson correlation coefficients between surface-gridded temperatures from the Reanalysis project ${ }^{33}$ and sea ice area in the Barents and Kara seas. Period is $1982-2005$, for

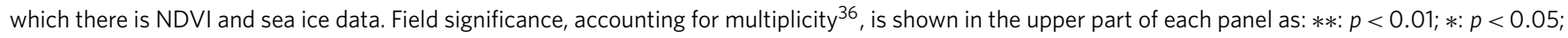
NS, not significant. Note the disappearance of the relationship in NWET as the growing season advances and sea ice position recedes further away from the coast.

on the northward migration of southern individuals and would therefore occur much slower.

Our data show that vegetation response to climate warming is not restricted to Arctic processes such as snow albedo and sea-ice-related amplification mechanisms ${ }^{5,8}$ but extends also to climatic patterns linked to the position of mid-troposphere air masses over Eurasia (Fig. 4 and Supplementary Fig. S3). Whereas late-spring tundra productivity and temperatures are still largely linked to declining sea ice extent in seas adjacent to NWET (Fig. 2), vegetation growth at the peak of the growing season is decoupled from sea ice and responds strongly to the position of synoptic weather systems with clear links to lower latitudes. Significantly, secondary growth of woody vegetation, which is responsible for the size of the individuals and thus for potential transitions from low erect shrubs to tall tree-sized growth forms, takes place during this latter period, thus not being dependent on what occurs in the Arctic Ocean and adjacent seas. Although such decoupling might be so far unique to NWET owing to the low sea ice cover in the Barents Sea, it has the potential to become a prevailing pattern of vegetation/climate relationships in a warmer Arctic as the position of sea ice continues to recede earlier in the spring and its ability to influence peak growing season temperatures decreases.

Whereas annual shrub growth is controlled by summer temperature, the spatial distribution of tall shrubs in NWET is topographically restricted to sheltered locations where snow depth in winter provides protection from abrasion and desiccation ${ }^{18}$. Large increases in the number of days with deep snow cover $(2-6 \mathrm{~cm}$ per decade; ref. 22) and trends towards earlier spring snowmelt have been reported since 1966/7 (ref. 23) in NWET, whereas late-twentyfirst-century climatic projections predict a continuation of such trends in the Barents region, with an $18 \%$ increase in precipitation anticipated for the period 2080-2099 relative to 1981-2000, largest in winter ${ }^{24}$. Moreover, tall shrubs trap snow, enhancing snow depth and reducing winter snow loss due to sublimation ${ }^{2}$. Sheltered, tall shrub-favourable locations result from erosive processes operating over different spatial and temporal scales, such as fluvial valleys and cryogenic landslides. Whereas fluvial landscapes are dominant west of the Urals, cryogenic landslides are the leading landscapeforming process in the continuous permafrost zone of northwestern Siberia $^{18}$. Cryogenic landslides are controlled by the depth of summer thaw (hence, temperature) and water content, which within substrates of comparable texture depends on precipitation and rate of thaw ${ }^{25}$. Ongoing climatic trends and predictions suggest an increase and a northward displacement of permafrost-related landslide activity, potentially favouring the expansion of willows ${ }^{18}$.

Regardless of whether climate change eventually results in a spatial expansion of tall shrub thickets, as has been observed at lower latitudes in our study region ${ }^{26}$ and over a range of locations in other regions within the Low Arctic ${ }^{2,3,27}$, contemporary tall shrub individuals are already tree-sized, free of grazing pressure ${ }^{6}$ and cover $6-13 \%$ of the Low Arctic of NWET. These alone represent a significant ecosystem transformation already underway. The processes we report here for NWET suggest a large-scale shift towards a structurally novel ecosystem absent for millennia, which shares many characteristics with that described for Beringia in the early Holocene epoch ${ }^{28}$. This structurally complex mosaic of open woodland characterized by thickets of tree-sized $(>2 \mathrm{~m}$ ) individuals of deciduous broad-leaved taxa has the potential of significantly altering abiotic and biotic conditions within the Low Arctic ${ }^{3}$, and is already modifying reindeer herd management practices ${ }^{14}$.

Low Arctic tundra is dominated by woody taxa with wide growth-form variability partly due to phenotypic variation ${ }^{28}$. Observed changes in northern Eurasia agree with predictions of potential in situ rapid shifts from low to high shrubs or trees and the appearance of structurally novel biomes under a warming scenario ${ }^{28,29}$. This process occurs over decades, whereas 


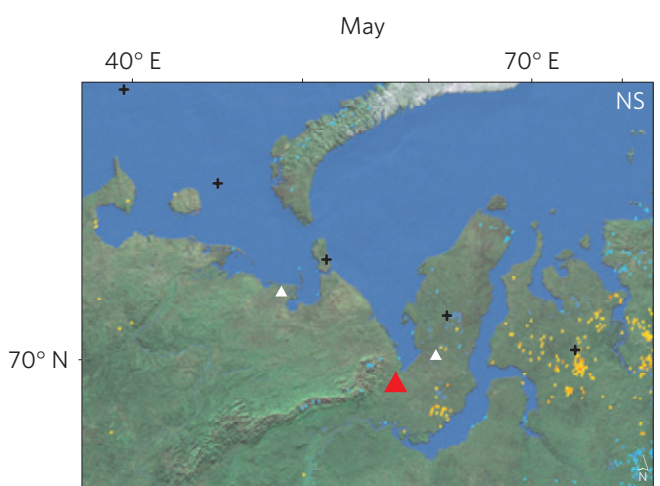

July

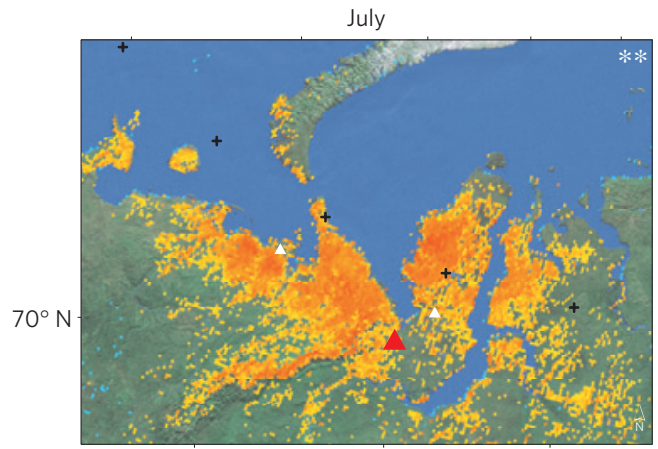

$60^{\circ} \mathrm{E}$

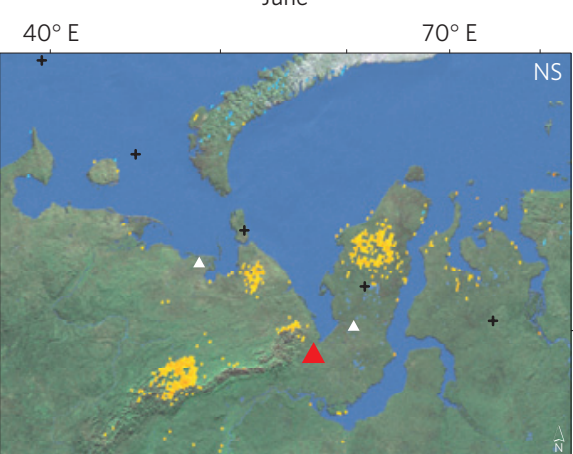

August

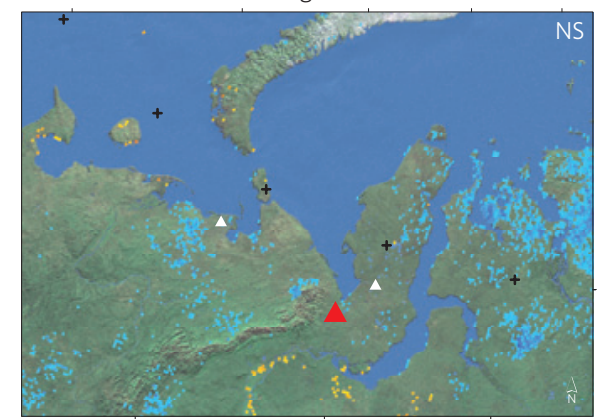

$60^{\circ} \mathrm{E}$

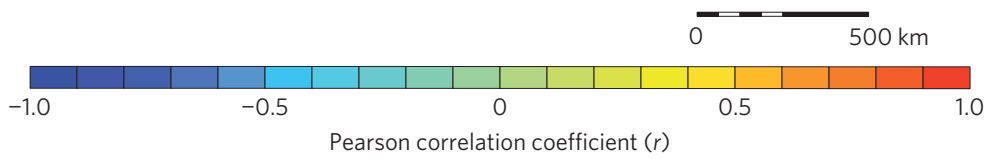

Figure 3 | Monthly Pearson correlation coefficients ( $r$ ) between NDVI (ref. 11) and Laborovaya (S. lanata) shrub ring-width chronology. Red triangle shows the location of the Laborovaya site. Period is 1982-2005, for which there is NDVI data. Only significant ( $p<0.05$ ) correlations are shown. Field significance, accounting for multiplicity ${ }^{36}$, is shown in the upper part of each panel as: $* *: p<0.01$; NS, not significant. Note: the short period over which correlations are widespread (July); and the correlation between the ring-width chronology and distant highly productive areas to the north and west is higher than that to proximal sandy low-productivity areas to the east. Biweekly correlations, not shown here for brevity, show even higher values for the second half of June and the first half of July. Calculations for the remaining chronologies show the same pattern and are available in Supplementary Fig. S1.

migration-based boreal treeline advances in Eurasia have lagged climate at centennial timescales in the fastest cases ${ }^{29}$. Present constraints to boreal forest advance include lower insolation, cold maritime conditions from Arctic coastline proximity, and rich organic soils that may preclude tree establishment ${ }^{29}$. Moreover, past rapid treeline advances were related to existing sparse tree populations (refugia) from where trees expanded during periods of favourable conditions ${ }^{30}$. In NWET, away from the valleys of smaller waterways flowing south into the Ob bay, such as the Shchuch'e River, no small populations of boreal coniferous trees are known to exist in the tundra north of the latitudinal treeline ${ }^{31}$. Thus, a northward advance of boreal forest would probably be significantly delayed. Whereas Earth system models have traditionally predicted an encroachment of boreal forest into tundra ${ }^{32}$, such a biome-based view might not be the most probable outcome for the twentyfirst-century tundra. A heterogeneous phenotypic intra-species vegetation response to environmental change is more likely.

Patterns of response to climate by Low Arctic shrub vegetationmainly willow but also alder at one site-suggest that a rapid transition is already underway in NWET, which has analogues in the northern Eurasian palaeoecological record from the early Holocene, and is likely to take place in the remaining tundra regions as Arctic warming progresses. Owing to its suite of ecological and environmental characteristics, unique for the time being within the tundra biome, NWET emerges as a bellwether region for future pathways of Arctic ecosystems.

\section{Methods}

Climatic data. In NWET, climatic data north of the treeline is patchy, spatially and temporally, and distances between stations can be great. Monthly precipitation and temperature data from Russian Arctic stations located near our study sites (that is, $<400 \mathrm{~km}$; Fig. 1) were available for 1961-2005 at the National Snow and Ice Data Centre at Boulder, Colorado. We also used mean monthly surface temperature from a $2.5^{\circ}$ latitude per $2.5^{\circ}$ longitude regional grid covering the period 1948-2005 from the NCEP Reanalysis database ${ }^{33}$, provided by the NOAA-CIRES Climate Diagnostics Centre, Boulder, Colorado (http://www.cdc.noaa.gov/). Monthly indices of the SCA were obtained from the Climate Prediction Centre of the National Oceanic and Atmospheric Administration (http://www.cpc.ncep.noaa. gov/data/), covering the period 1950-2005.

Sea ice data. Data on monthly total ice covered area spanning the SMMR-SSM/I record from October 1978 to the most recent processing date were provided by J. Comiso of the NASA Goddard Space Flight Centre, Oceans and Ice Branch, and produced from the Bootstrap Sea Ice Concentrations from Nimbus-7 SMMR and DMSP SSM/I data set (http://nsidc.org/data/nsidc-0079.html).

Remote sensing data and land cover classification. NDVI data were derived from the NOAA AVHRR meteorological satellites. We obtained biweekly NDVI records from the GIMMS data set, available through the Global Land Cover Facility ${ }^{11}$ (http://glcf.umiacs.umd.edu/data/gimms/). The data set has been corrected for calibration, view geometry, volcanic aerosols and other effects not related to vegetation change, and covers the period $1981-2005$ at $8 \mathrm{~km}$ resolution. Moderate-Resolution Image Spectroradiometer imagery at 16 -day intervals and $250 \mathrm{~m}$ resolution was obtained for the period 2000-2011 (http://modis-land.gsfc.nasa.gov/vi.htm) to analyse NDVI patterns along different landscape units for regions defined as the $50 \times 50 \mathrm{~km}$ area around each site (Supplementary Fig. S6). Finally, 1-m-resolution imagery was acquired for an area $\sim 40 \mathrm{~km}^{2}$ around each sampling site: they consisted of VHR images from Quickbird-2 (Varandei, 05/08/2005; Laborovaya, 11/07/2005) 
a

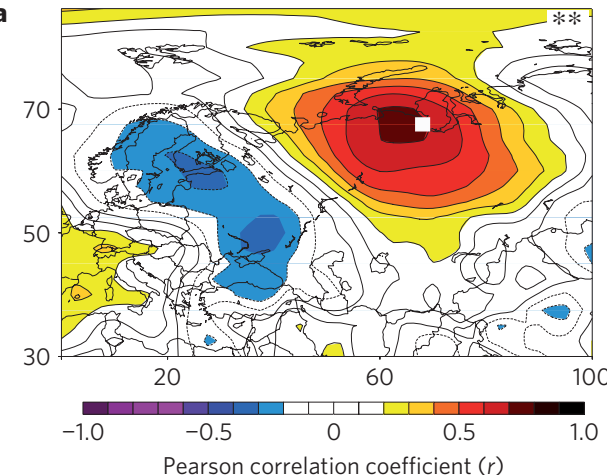

b
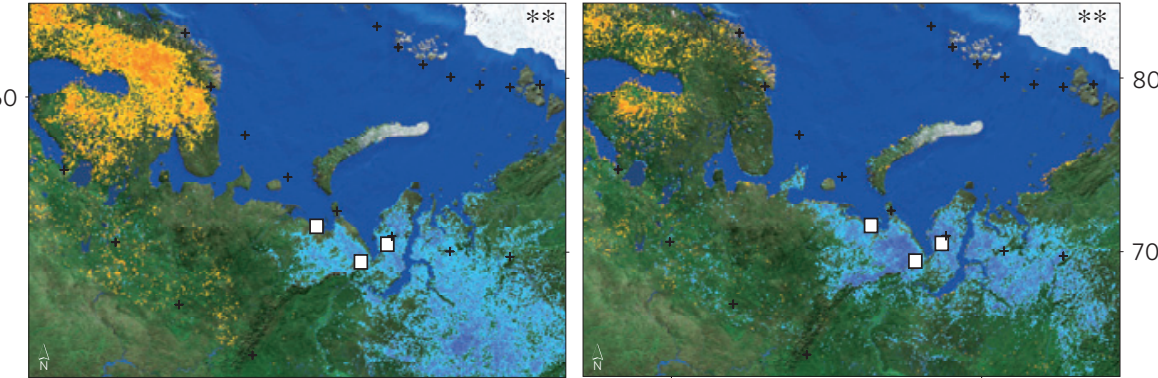

50

80

50

80

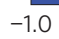

$-0.5$

Pearson correlation coefficient $(r)$

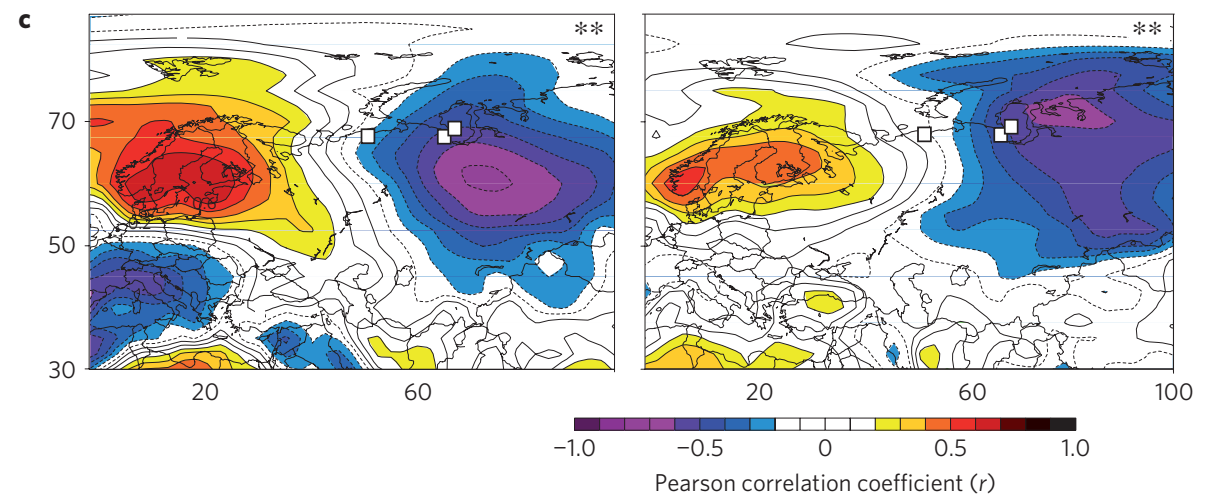

Figure 4 | a, Pearson correlation coefficients between surface-gridded temperatures from the Reanalysis project ${ }^{33}$ and Laborovaya (S. lanata) ring-width chronology. Correlations are computed between the chronology and the growing season period for which significant response function coefficients were

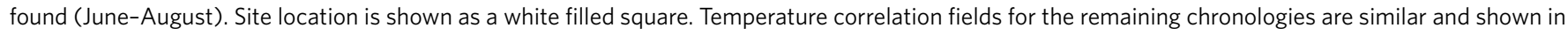
Supplementary Fig. S3. b, Pearson correlation coefficients between NDVI (ref. 11) and the SCA index (http://www.cpc.ncep.noaa.gov/data/): June Scandinavian index versus second half of June NDVI (left), June Scandinavian index versus first half of July NDVI (right). c, Monthly Pearson correlation coefficients between surface-gridded temperatures from the Reanalysis project and the SCA index for June (left) and July (right). Sites are shown as filled white squares. Only significant $(p<0.05)$ correlations are shown. Field significance, accounting for multiplicity ${ }^{36}$, is shown in the upper part of each panel as: $* *: p<0.01$. Note the clear correspondence between shrub growth versus temperature correlation fields and the Scandinavian index.

and Worldview-2 (Yuribei, 19/07/2010). For each site, a land cover classification was made, using the satellite imagery together with information collected on location to calibrate remote-sensing data (Supplementary Fig. S6).

Building of dendrochronologies. Dendrochronologies were obtained from three separate sites in the Low Arctic of NWET, namely Varandei $\left(68.65^{\circ} \mathrm{N}, 58.38^{\circ} \mathrm{E}\right)$, Laborovaya $\left(67.67^{\circ} \mathrm{N}, 68.00^{\circ} \mathrm{E}\right)$ and Yuribei River $\left(68.91^{\circ} \mathrm{N}, 70.23^{\circ} \mathrm{E}\right.$; Fig. 1$)$

Slices 2-3-cm-thick were collected from 24 to 40 discrete individuals spread across each sample site in the summers of 2006, 2007 and 2010. Care was used in not taking stems from the same copses, thus trying to minimize the effect of sampling clones. A minimum of four slices between the root collar and the upper canopy was taken from each individual to properly account for reaction wood. Wood samples were sanded and measured with a precision of $0.01 \mathrm{~mm}$. Cross-dating of the ring width measurement series was performed following standard dendrochronological procedures $^{34}$. Ring width measurements were detrended using a 32-year smoothing spline. Expressed population signal, which is a function of series replication and mean inter-series correlation, was used to define the reliable part of the chronology (expressed population signal $>0.85$; ref. 34 ). Other descriptive statistics were calculated for each chronology to permit comparisons with other dendrochronological data sets ${ }^{34}$ (Supplementary Table S1).

Relationships between environmental variables. Response functions between the ring-width residual chronologies and monthly climate data (temperature and precipitation) for the four closest climate stations (distance to the site $<400 \mathrm{~km}$; Fig. 1) were computed using the program DendroClim2002 (ref. 35) for the period 1961-2005, for which full climatic and dendrochronological data were available. Response function coefficients are multivariate estimates from a principal component regression model calculated to avoid colinearity between predictors, commonly found in multivariable sets of meteorological data. Significance and stability of coefficients were assessed by 1,000 bootstrap estimates obtained by 
random extraction with replacement from the initial data set. Climate-growth relationships were analysed from September of the year before the growing season to August of the growth year. Relationships between ring-width indices, NDVI data, sea ice cover, temperature and the SCA were assessed by linear Pearson's correlation coefficients. Field significance, accounting for the effects of multiplicity in spatially autocorrelated fields, was addressed following the Monte-Carlo-based approach (based on 1,000 iterations) described previously ${ }^{36}$.

\section{Received 28 November 2011; accepted 30 April 2012;} published online XX Month XXXX

\section{References}

1. Goetz, S. J., Bunn, A. G., Fiske, G. J. \& Houghton, R. A. Satellite-observed photosynthetic trends across boreal North America associated with climate and fire disturbance. Proc. Natl Acad. Sci. USA 102, 13521-13525 (2005).

2. Sturm, M., Racine, C. \& Tape, K. Climate change-increasing shrub abundance in the Arctic. Nature 411, 546-547 (2001).

3. Elmendorf, S. C. et al. Plot-scale evidence of tundra vegetation change and links to recent summer warming. Nature Clim. Change http://dx.doi.org/10 1038/nclimate1465 (advance online publication, 2012).

4. Epstein, H. E., Walker, D. A., Raynolds, M. K., Jia, G. J. \& Kelley, A. M Phytomass patterns across a temperature gradient of the North American Arctic tundra. J. Geophys. Res. 113, http://dx.doi.org/10.1029/2007jg000555 (2008).

5. Bhatt, U. S. et al. Circumpolar Arctic tundra vegetation change is linked to sea ice decline. Earth Inter. 14, 1-20 (2010).

6. Forbes, B. C., Macias Fauria, M. \& Zetterberg, P. Russian Arctic warming and 'greening' are closely tracked by tundra shrub willows. Glob. Change Biol. 16, 1542-1554 (2010).

7. Walker, M. D. et al. Plant community responses to experimental warming across the tundra biome. Proc. Natl Acad. Sci. USA 103, 1342-1346 (2006).

8. Serreze, M. C. \& Barry, R. G. Processes and impacts of Arctic amplification: A research synthesis. Glob. Planet. Change 77, 85-96 (2011).

9. Raynolds, M. K., Comiso, J. C., Walker, D. A. \& Verbyla, D. Relationship between satellite-derived land surface temperatures, arctic vegetation types, and NDVI. Remote Sens. Environ. 112, 1884-1894 (2008).

10. Bengtsson, L., Semenov, V. A. \& Johannessen, O. M. The early twentieth-century warming in the Arctic—a possible mechanism. J. Clim. 17, 4045-4057 (2004).

11. Tucker, C. J. et al. An extended AVHRR 8-km NDVI dataset compatible with MODIS and SPOT vegetation NDVI data. Int. J. Remote Sens. 26, 4485-4498 (2005).

12. Walker, D. A. et al. The circumpolar arctic vegetation map. J. Vegetation Sci. 16, 267-282 (2005).

13. Raynolds, M. K., Walker, D. A. \& Maier, H. A. NDVI patterns and phytomass distribution in the circumpolar Arctic. Remote Sens. Environ. 102, 271-281 (2006).

14. Forbes, B. C. \& Stammler, F. Arctic climate change discourse: The contrasting politics of research agendas in the West and Russia. Polar Res. 28, 28-42 (2009).

15. Forbes, B. C. et al. High resilience in the Yamal-Nenets social-ecological system, West Siberian Arctic, Russia. Proc. Natl Acad. Sci. USA 106, 22041-22048 (2009)

16. Barnston, A. G. \& Livezey, R. E. Classification, seasonality and persistence of low-frequency atmospheric circulation patterns. Mon. Weath. Rev. 115, 1083-1126 (1987)

17. Bueh, C. \& Nakamura, H. Scandinavian pattern and its climatic impact. Q. J. R. Meteorol. Soc. 133, 2117-2131 (2007).

18. Walker, D. A. et al. Spatial and temporal patterns of greenness on the Yamal Peninsula, Russia: Interactions of ecological and social factors affecting the Arctic normalized difference vegetation index. Environ. Res. Lett. 4, http://dx. doi.org/10.1088/1748-9326/4/4/045004 (2009).

19. Drozdov, D. S. et al. Electronic atlas of the Russian Arctic coastal zone. Geo-Mar. Lett. 25, 81-88 (2005).
20. Arft, A. M. et al. Responses of tundra plants to experimental warming: Meta-analysis of the international tundra experiment. Ecol. Monogr. 69, 491-511 (1999).

21. Howe, G. T. et al. From genotype to phenotype: Unraveling the complexities of cold adaptation in forest trees. Can. J. Botany 81, 1247-1266 (2003).

22. Bulygina, O. N., Razuvaev, V. N. \& Korshunova, N. N. Changes in snow cover over Northern Eurasia in the last few decades. Environ. Res. Lett. 4, http://dx. doi.org/10.1088/1748-9326/4/4/045026 (2009).

23. Brown, R., Derksen, C. \& Wang, L. A multi-data set analysis of variability and change in Arctic spring snow cover extent, 1967-2008. J. Geophys. Res. 115, D16111 (2010).

24. Göttel, H. et al. Influence of changed vegetations fields on regional climate simulations in the Barents Sea Region. Climatic Change 87, 35-50 (2008).

25. Leibman, M. O. Cryogenic landslides on the Yamal Peninsula, Russia: Preliminary observations. Permafrost Periglac. Process. 6, 259-264 (1995).

26. Shiyatov, S. G., Terent'ev, M. M. \& Fomin, V. V. Spatiotemporal dynamics of forest-tundra communities in the Polar Urals. Russian J. Ecol. 36, 69-75 (2005).

27. Tape, K., Sturm, M. \& Racine, C. The evidence for shrub expansion in Northern Alaska and the Pan-Arctic. Glob. Change Biol. 12, 686-702 (2006).

28. Edwards, M. E., Brubaker, L. B., Lozhkin, A. V. \& Anderson, P. M. Structurally novel biomes: A response to past warming in Beringia. Ecology 86, 1696-1703 (2005).

29. MacDonald, G. M., Kremenetski, K. V. \& Beilman, D. W. Climate change and the northern Russian treeline zone. Phil. Trans. R. Soc. B 363, 2283-2299 (2008).

30. Payette, S., Eronen, M. \& Jasinski, J. J. P. The circumboreal tundra-taiga interface: Late pleistocene and holocene changes. Ambio 15-22 (2002).

31. Hantemirov, R. M. \& Shiyatov, S. G. A continuous multimillennial ring-width chronology in Yamal, northwestern Siberia. Holocene 12, 717-726 (2002).

32. Kaplan, J. O. et al. Climate change and Arctic ecosystems: 2. Modeling, paleodata-model comparisons, and future projections. J. Geophys. Res. 108, 8171 (2003).

33. Kalnay, E. et al. The NCEP/NCAR 40-year reanalysis project. Bull. Am. Meteorol. Soc. 77, 437-471 (1996).

34. Cook, E. R. \& Kairiukstis, L. A. 408 (Springer, 1990).

35. Biondi, F. \& Waikul, K. DENDROCLIM2002: A C++ program for statistical calibration of climate signals in tree-ring chronologies. Comput. Geosci. 30, 303-311 (2004).

36. Livezey, R. E. \& Chen, W. Y. Statistical field significance and its determination by Monte Carlo techniques. Month. Weath. Rev. 111, 46-59 (1983).

\section{Acknowledgements}

The overall work was supported by the National Aeronautics and Space Administration (grants NNG6GE00A and NNX09AK56G), the Northern Eurasian Earth Science Partnership Initiative, the Academy of Finland's Russia in Flux program through the ENSINOR project (decision 208147), the National Science Foundation Office of Polar Programs (grant 0531200) and the Nordic Centre of Excellence-TUNDRA. M.M.-F was financially supported by a Marie Curie Research Fellowship during the completion of this study (Grant Agreement Number 254206, project ECOCHANGE: Creating conditions for persistence of biodiversity in the face of climate change).

\section{Author contributions}

M.M-F. performed the statistical analysis, wrote the manuscript and created the figures. B.C.F. designed and performed the field expeditions and sampling, supervised the project and collaborated in writing the manuscript. P.Z. dated and measured the ring-width chronologies. T.K. performed fieldwork (ground truthing of satellite imagery) and laboratory remote-sensing analyses.

\section{Additional information}

The authors declare no competing financial interests. Supplementary information accompanies this paper on www.nature.com/natureclimatechange. Reprints and permissions information is available online at www.nature.com/reprints. Correspondence and requests for materials should be addressed to B.C.F. 